\title{
A Tetranuclear Fluorido-Bridged Iron Compound: Fluoride Abstraction from the Tetrafluoridoborate Anion
}

\author{
Feng Jiang, ${ }^{\dagger}$ Maxime A. Siegler, ${ }^{\ddagger}$ and Elisabeth Bouwman $*,{ }^{\dagger}$
}

\begin{abstract}
$\dagger$ Leiden Institute of Chemistry, Gorlaeus Laboratories, Leiden University, P.O. Box 9502, 2300 RA Leiden, The Netherlands

‡ Department of Chemistry, Johns Hopkins University, 3400 N. Charles Street, Baltimore, Maryland 21218, United States

* Corresponding author: bouwman@lic.leidenuniv.nl
\end{abstract}

\begin{abstract}
The novel iron(II) fluoride cluster $\left[\mathrm{Fe}^{\mathrm{II}}{ }_{4}\left(\mathrm{~L}^{1} \mathrm{SSL}^{1}\right)_{2} \mathrm{~F}_{6}(\mathrm{MeCN})_{2}\right]\left(\mathrm{BF}_{4}\right)_{2} \quad\left(\mathrm{~L}^{1} \mathrm{SSL}^{1}=\right.$ di-2-(bis(2pyridylmethyl)amino)ethyl disulfide) has been synthesized by reaction of the ligand $\mathrm{L}^{1} \mathrm{SSL}^{1}$ with $\left[\mathrm{Fe}(\mathrm{MeCN})_{6}\right]\left(\mathrm{BF}_{4}\right)_{2}$. The crystal structure shows that a tetranuclear iron(II) compound is formed through the bridging of two dinuclear iron(II) units by four fluoride anions. The ${ }^{19} \mathrm{~F}$ NMR spectrum distinguishes both the terminal and bridging fluoride ions in this compound. The new compound is a rare $\mathrm{Fe}^{\mathrm{II}}$ fluoride cluster with four $\mathrm{Fe}^{\mathrm{II}}$ and four $\mathrm{F}^{-}$ions arranged in a nearly perfect square plane, which obtained its fluoride ions from the tetrafluoridoborate anion.
\end{abstract}

Keywords: Iron(II) compound, Tetranuclear, Fluoride abstraction, Tetrafluoridoborate anion

The synthesis of transition metal fluoride compounds has received considerable attention in the last decades because of their special structural characteristics and potential application in the field of magnetic materials [1-3]. Two main strategies have been employed to synthesize metal fluoride compounds: the first one is based on the addition of fluoride salts like $\mathrm{NaF}$ or $\mathrm{AsF}_{3}$ as fluorinating agents; the other one is based on the use of metal tetrafluoridoborate as starting salts, which generate fluoride ions upon decomposition. In the last decades, tremendous efforts have been put in the synthesis of copper(II) fluoride compounds from copper tetrafluoridoborate [4-7]. Recently, Reger et al. reported the synthesis of a series of linear dinuclear $\mathrm{Fe}^{\mathrm{II}}, \mathrm{Co}^{\mathrm{II}}, \mathrm{Ni}^{\mathrm{II}}, \mathrm{Cu}^{\mathrm{II}}, \mathrm{Zn}^{\mathrm{II}}, \mathrm{Cd}^{\mathrm{II}}$ compounds starting from the respective metal tetrafluoridoborate salts, where two metal ions are bridged by one fluoride ion forming a M-F-M configuration [8, 9]. Besides that, two dinuclear fluorido-bridged zinc and cadmium compounds were synthesized based on a porphyrin ligand by the group of Sessler [10]. Most of these metal fluoride compounds are stabilized by hydrogen-bond interactions or they are the linear compounds (M-F-M). In this communication we report a novel tetranuclear $\mathrm{Fe}^{\mathrm{II}}$ fluoride cluster obtained by reaction of a disulfide ligand with iron(II) tetrafluoridoborate. 
The ligand di-2-(bis(2-pyridylmethyl)amino)ethyl disulfide $\left(\mathrm{L}^{1} \mathrm{SSL}^{1}\right)$ was synthesized via the reported procedure [11, 12]. Under an inert atmosphere, treatment of the disulfide ligand $\mathrm{L}^{1} \mathrm{SSL}^{1}$ with $\left[\mathrm{Fe}(\mathrm{MeCN})_{6}\right]\left(\mathrm{BF}_{4}\right)_{2}$ in acetonitrile at room temperature results in a brownish purple solution from which the compound $\left[\mathrm{Fe}^{\mathrm{II}}{ }_{4}\left(\mathrm{~L}^{1} \mathrm{SSL}^{1}\right)_{2} \mathrm{~F}_{6}(\mathrm{MeCN})_{2}\right]\left(\mathrm{BF}_{4}\right)_{2}$ was isolated in a yield of $42 \%$ (scheme 1 ). The compound was characterized by single crystal X-ray crystallography, electrospray ionization mass spectrometry (ESI-MS), elemental analysis, UV-Vis and nuclear magnetic resonance (NMR) spectroscopy.

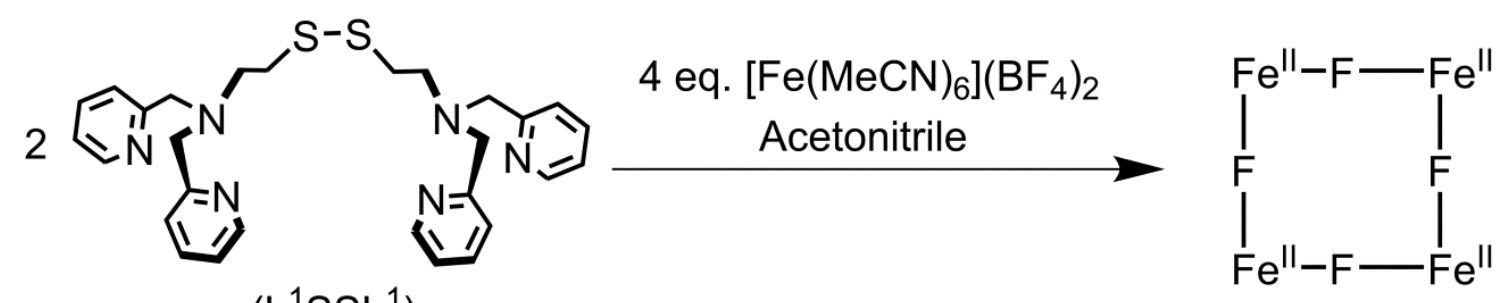

$\left(L^{1} S S L^{1}\right)$

Scheme 1. Schematic overview of the reaction of the ligand $\mathrm{L}^{1} \mathrm{SSL}^{1}$ with $\left[\mathrm{Fe}(\mathrm{MeCN})_{6}\right]\left(\mathrm{BF}_{4}\right)_{2}$ in acetonitrile. The structure drawing is simplified for clarity.

Single crystals of the compound $\left[\mathrm{Fe}^{\mathrm{II}} 4\left(\mathrm{~L}^{1} \mathrm{SSL}^{1}\right)_{2} \mathrm{~F}_{6}(\mathrm{MeCN})_{2}\right]\left(\mathrm{BF}_{4}\right)_{2}$ suitable for X-ray structure determination were obtained by slow vapor diffusion of diethyl ether into an acetonitrile solution containing the compound. A projection of the compound is given in Figure 1; additional information about the refinement is provided in the Supporting Information Table S1 and selected bond distances and angles are given in Table 1 . The compound $\left[\mathrm{Fe}_{4}{ }_{4}\left(\mathrm{~L}^{1} \mathrm{SSL}^{1}\right)_{2} \mathrm{~F}_{6}(\mathrm{MeCN})_{2}\right]\left(\mathrm{BF}_{4}\right)_{2}$ crystallizes in the monoclinic space group $C 2 / c$, and only one half of the tetranuclear molecule is crystallographically independent in the asymmetric unit. The independent unit does not simply contain a dinuclear compound built from one disulfide ligand and two iron(II) centers, but rather two times half of such a dinuclear compound, linearly bridged by one fluoride ion $\left(\mathrm{Fe} 1-\mathrm{F} 1-\mathrm{Fe} 2=163.62(10)^{\circ}, \mathrm{Fe} 1-\mathrm{F} 1-\mathrm{Fe} 2^{*}=\right.$ $\left.166.88(10)^{\circ}\right)$. The tetranuclear compound with two-fold rotation symmetry is formed via bridging fluoride ions, with the two-fold rotation axis passing perpendicular through the $\mathrm{Fe}_{4} \mathrm{~F}_{4}$ plane. Each iron(II) center is coordinated by three facially-bound nitrogen donor atoms of the ligand and two fluoride ions bridging to two other iron centers. A nitrogen atom of acetonitrile occupies the sixth coordination site for the Fe1 centers, whereas the octahedral geometry of the $\mathrm{Fe} 2$ ion is completed with an additional terminal fluoride ion. The bond distances between Fe and $\mathrm{N}$ range from 2.122(2) to 2.236(2) $\AA$, indicating a high-spin state $(S=2)$ of the $\mathrm{Fe}^{\mathrm{II}}$ centers $[13,14]$. The bond distance between Fe2 and the terminal fluoride ion F3 is 1.8234(16), and the bond distances between Fe2 and the bridging fluoride ions F1 and F2 are 1.9032(14) and 1.8970(14), respectively. Remarkably, all bond lengths of the iron(II) center Fe1 are slightly longer than the bond lengths of Fe2. Specifically, the bond distances between Fe1 and the bridging F1 and F2 ions are 2.0110(14) and 2.0618(14), respectively. The four iron(II) centers and the four bridging fluoride ions together form a nearly planar 
arrangement, with the octahedral iron centers at the corners of the square. The terminally coordinated apical fluoride ions bound to Fe2 both reside on one side of the plane, whereas the apically bound acetonitrile molecules on Fe1 are located on the other side of the plane. The diethyl-disulfide bridging the two amine nitrogens within one ligand $\mathrm{L}^{1} \mathrm{SSL}^{1}$ connect two opposite corners of the square plane.

$\mathrm{UV}-\mathrm{Vis}$ spectra of the compound $\left[\mathrm{Fe}_{4}{ }_{4}\left(\mathrm{~L}^{1} \mathrm{SSL}^{1}\right)_{2} \mathrm{~F}_{6}(\mathrm{MeCN})_{2}\right]\left(\mathrm{BF}_{4}\right)_{2}$ dissolved in acetonitrile present two absorption bands, one at $258 \mathrm{~nm}\left(11 \times 10^{3} \mathrm{M}^{-1} \mathrm{~cm}^{-1}\right)$ arising from $\pi^{*} \leftarrow \pi$ transitions of the pyridyl groups, and one at $349 \mathrm{~nm}\left(1.2 \times 10^{3} \mathrm{M}^{-1} \mathrm{~cm}^{-1}\right)$ likely corresponding to an $\mathrm{N} \leftarrow$ Fe charge transfer transition (MLCT) (Figure S1). ESI-MS spectra of the compound dissolved in acetonitrile show peaks $(\mathrm{m} / \mathrm{z})$ at 333.3 and 685.2 corresponding to the dicationic and monocationic species $\left[\mathrm{Fe}^{\mathrm{II}}{ }_{2}\left(\mathrm{~L}^{1} \mathrm{SSL}^{1}\right) \mathrm{F}_{2}\right]^{2+}$ and $\left[\mathrm{Fe}_{2}{ }_{2}\left(\mathrm{~L}^{1} \mathrm{SSL}^{1}\right) \mathrm{F}_{3}\right]^{+}$, respectively (Figure $\mathrm{S} 2$ ). ${ }^{1} \mathrm{H}$ NMR spectroscopy of the compound $\left[\mathrm{Fe}_{4}{ }_{4}\left(\mathrm{~L}^{1} \mathrm{SSL}^{1}\right)_{2} \mathrm{~F}_{6}(\mathrm{MeCN})_{2}\right]\left(\mathrm{BF}_{4}\right)_{2}$ dissolved in acetonitrile- $\mathrm{d}_{3}$ resulted in a spectrum with broad resonances down to around $90 \mathrm{ppm}$ (Figure S3), in agreement with the presence of high-spin Fe(II) ions as deduced from the bond distances. The ${ }^{19} \mathrm{~F}$ NMR spectrum of the compound $\left[\mathrm{Fe}^{\mathrm{II}}{ }_{4}\left(\mathrm{~L}^{1} \mathrm{SSL}^{1}\right)_{2} \mathrm{~F}_{6}(\mathrm{MeCN})_{2}\right]\left(\mathrm{BF}_{4}\right)_{2}$ presents a strong sharp peak at $136 \mathrm{ppm}$ that is assigned to the fluorine atoms of the $\mathrm{BF}_{4}{ }^{-}$anions, as well as two broad peaks with lower intensity at 160 and $190 \mathrm{ppm}$, which likely correspond to the terminal fluoride ions F3 and the bridging fluoride ions F1 and F2, respectively (Figure S4) $[15,16]$. A SQUID measurement was conducted for the compound in the range $2-300 \mathrm{~K}$, showing the $\chi_{\mathrm{M}} \mathrm{T}$ value at $300 \mathrm{~K}$ to be $11.60 \mathrm{~cm}^{3} \mathrm{~mol}^{-1} \mathrm{~K}$, showing only a small antiferromagnetic interaction (Figure S5). The value at $300 \mathrm{~K}$ is only slightly smaller than the theoretical value estimated from four isolated high-spin state $(S=4)$ iron(II) centers in octahedral geometries, $\left(\chi_{\mathrm{M}} \mathrm{T}=12.0 \mathrm{~cm}^{3} \mathrm{~mol}^{-1} \mathrm{~K}\right.$ for $\left.\mathrm{g}=2\right)$ [17].

In a previous study, we reported a tetranuclear $\mathrm{Cu}^{\mathrm{II}}$ fluoride compound formed from a similar dinucleating disulfide ligand and copper(II) tetrafluoridoborate [5]. The crystal structure showed that the two dinuclear copper(II) units in this compound are symmetrically bridged by water, fluoride, and tetrafluoridoborate anions. This copper(II) fluoride cluster features additional hydrogen-bond interactions between the fluoride ions and coordinated water molecules [5].

In many cases it appears that hydrogen-bond interactions are vital to stabilize such macrocyclic metal fluoride compounds. For example, the group of Sessler reported fluorido-bridged zinc and cadmium compounds, for which the authors suggest the hydrogen-bond interactions between the protons of the non-coordinating pyrole rings in the ligand and the fluoride ions to play an important role in the stabilization of the compounds [10]. Apparently, our compound $\left[\mathrm{Fe}_{4}{ }_{4}\left(\mathrm{~L}^{1} \mathrm{SSL}^{1}\right)_{2} \mathrm{~F}_{6}(\mathrm{MeCN})_{2}\right]\left(\mathrm{BF}_{4}\right)_{2}$ does not need such stabilization, as it does not contain any potential hydrogen-bond donors. 




Figure 1. Displacement ellipsoid plots ( $50 \%$ probability level) of the cationic part of the compound $\left[\mathrm{Fe}_{4}{ }_{4}\left(\mathrm{~L}^{1} \mathrm{SSL}^{1}\right)_{2} \mathrm{~F}_{6}(\mathrm{MeCN})_{2}\right]\left(\mathrm{BF}_{4}\right)_{2}$ at $110(2) \mathrm{K}$. Hydrogen atoms, $\mathrm{BF}_{4}^{-}$counter ions, and disorder are omitted for clarity. Carbon atoms are shown using the wireframe style.

Table 1. Selected bond distances $(\AA)$ and angles $\left(^{\circ}\right)$ of the compound $\left[\mathrm{Fe}^{\mathrm{II}}{ }_{4}\left(\mathrm{~L}^{1} \mathrm{SSL}^{1}\right)_{2} \mathrm{~F}_{6}(\mathrm{MeCN})_{2}\right]\left(\mathrm{BF}_{4}\right)_{2}$.

\begin{tabular}{llll}
\hline \multicolumn{4}{c}{ Selected bond distances ( $\AA$ ) } \\
\hline Fe1-F1 & $2.0110(14)$ & Fe2-F1 & $1.9032(14)$ \\
Fe1-F2 & $2.0618(14)$ & Fe2-F2 & $1.8970(14)$ \\
Fe1-N1 & $2.236(2)$ & Fe2-N2 & $2.228(6)$ \\
Fe1-N11 & $2.122(2)$ & Fe2-N31 & $2.109(6)$ \\
Fe1-N21 & $2.163(2)$ & Fe2-N41 & $2.143(6)$ \\
Fe1-N1S & $2.127(3)$ & Fe2-F3 & $1.8234(16)$ \\
Fe1-Fe2 & $3.8744(5)$ & Fe2*-Fe1 & $3.9329(5)$ \\
\hline \multicolumn{4}{c}{ Selected bond angles ( $)$} \\
\hline F1-Fe1-F2 & $82.68(6)$ & F2-Fe2-N31 & $92.1(3)$ \\
F1-Fe1-N1S & $98.33(8)$ & F2-Fe2-N41 & $167.5(6)$ \\
F1-Fe1-N11 & $166.54(7)$ & F2-Fe2-N2 & $91.1(3)$ \\
F1-Fe1-N21 & $86.65(7)$ & F2-Fe2-F1 & $95.05(6)$ \\
F1-Fe1-N1 & $94.64(7)$ & F2-Fe2-F3 & $101.61(7)$ \\
F2-Fe1-N1S & $93.41(8)$ & N31-Fe2-N41 & $81.8(6)$ \\
F2-Fe1-N11 & $87.49(7)$ & N31-Fe2-N2 & $79.9(5)$ \\
F2-Fe1-N21 & $168.72(7)$ & N31-Fe2-F1 & $164.4(4)$ \\
F2-Fe1-N1 & $100.86(7)$ & N31-Fe2-F3 & $94.2(4)$ \\
N1S-Fe1-N11 & $91.39(9)$ & N41-Fe2-N2 & $77.2(8)$ \\
N1S-Fe1-N21 & $91.75(9)$ & N41-Fe2-F1 & $88.5(5)$ \\
N1S-Fe1-N1 & $161.81(8)$ & N41-Fe2-F3 & $89.7(6)$ \\
N11-Fe1-N21 & $102.42(8)$ & N2-Fe2-F1 & $86.1(3)$ \\
N11-Fe1-N1 & $78.16(8)$ & N2-Fe2-F3 & $166.2(3)$ \\
N21-Fe1-N1 & $76.29(8)$ & F1-Fe2-F3 & $97.93(7)$ \\
Fe1-F1-Fe2 & $163.62(10)$ & Fe1-F2-Fe2 & $166.88(10)$ \\
\hline
\end{tabular}


Several mechanisms were put forward for the formation of metal fluoride compounds from tetrafluoridoborate salts, like strong-base assisted decomposition, hydrolysis, or Lewis-acid assisted fluoride abstraction $[9,18]$. As strong base or water was not present in our reaction, this excludes the first two mechanisms. The $\mathrm{BF}_{4}^{-}$decomposition pathway leading to our compound therefore is likely Lewis-acid assisted fluoride abstraction, which is similar to the mechanism suggested by the group of Sessler [10].

In conclusion, we have described the structure of a novel tetranuclear $\mathrm{Fe}^{\mathrm{II}}$ fluoride cluster with an unusual planar arrangement of the $\mathrm{Fe}_{4} \mathrm{~F}_{4}$ core, which is formed by the abstraction of fluoride ions from the tetrafluoridoborate anion.

Synthesis of the compound $\left[\mathrm{Fe}^{\mathrm{II}}{ }_{4}\left(\mathrm{~L}^{1} \mathrm{SSL}^{1}\right)_{2} \mathrm{~F}_{6}(\mathrm{MeCN})_{2}\right]\left(\mathrm{BF}_{4}\right)_{2}$ : To a pale-yellow solution of ligand $\mathrm{L}^{1} \mathrm{SSL}^{1}$ (51.95 mg, $\left.0.1 \mathrm{mmol}\right)$ in $5 \mathrm{~mL}$ acetonitrile, $95.10 \mathrm{mg}(0.2 \mathrm{mmol})$ [Fe(MeCN$\left.)_{6}\right]\left(\mathrm{BF}_{4}\right)_{2}$ was added, immediately resulting in a brownish purple solution. The acquired solution was stirred for about 3 hours, and then evaporated to $2 \mathrm{~mL}$. After that, $20 \mathrm{~mL}$ diethyl ether was added, and some brownish purple precipitate was formed. The precipitate was washed with diethyl ether $(4 \times 20 \mathrm{~mL})$. Yield: 35 mg, 42\%. IR (cm $\left.{ }^{-1}\right)$ : 645w, 725w, 763s, 788m, 1020vs, 1260w, 1446w, 1608s. ESI-MS found (calcd.) for $\left[\mathrm{Fe}^{\mathrm{II}}{ }_{2}\left(\mathrm{~L}^{1} \mathrm{SSL}^{1}\right) \mathrm{F}_{2}\right]^{2+} \mathrm{m} / \mathrm{z} 333.3$ (333.1); for $\left[\mathrm{Fe}^{\mathrm{II}}{ }_{2}\left(\mathrm{~L}^{1} \mathrm{SSL}^{1}\right) \mathrm{F}_{3}\right]^{+} \mathrm{m} / \mathrm{z} 685.2$ (685.1). Elemental analysis calcd (\%) for $\mathrm{C}_{56} \mathrm{H}_{64} \mathrm{~B}_{2} \mathrm{~F}_{14} \mathrm{Fe}_{4} \mathrm{~N}_{12} \mathrm{~S}_{4}+8 \mathrm{H}_{2} \mathrm{O}$ : C 39.83, H 4.78, N 9.95; found: C 39.92, H, 4.37, N, 9.47.

Single Crystal X-ray Crystallography: All reflection intensities were measured at 110(2) K using a SuperNova diffractometer (equipped with Atlas detector) with Mo $K \alpha$ radiation $(\lambda=0.71073 \AA$ ) under the program CrysAlisPro (Version 1.171.36.32 Agilent Technologies, 2013). The same program was used to refine the cell dimensions and for data reduction. The structure was solved with the program SHELXS-2013 (Sheldrick, 2008) and was refined on $F^{2}$ with SHELXL-2013 [1]. Analytical numeric absorption correction based on a multifaceted crystal model was applied using CrysAlisPro. The temperature of the data collection was controlled using the system Cryojet (manufactured by Oxford Instruments). The $\mathrm{H}$ atoms were placed at calculated positions using the instructions AFIX 23, AFIX 43 or AFIX 137 with isotropic displacement parameters having values 1.2 or 1.5 Ueq of the attached C atoms. The structure is partly disordered.

The Fe cluster is found at sites of twofold axial symmetry, and only one half of the molecule is crystallographically independent. The organic ligand coordinated to Fe2 (including the $\mathrm{N}-\mathrm{CH}_{2}-\mathrm{CH}_{2}-\mathrm{S}-\mathrm{S}-\mathrm{CH}_{2}-\mathrm{CH}_{2}-\mathrm{N}$ bridge) and one of the two $\mathrm{BF}_{4}^{-}$counter ions are found to be disordered over three orientations. All occupancy factors for each component of the disorder can be found in the CIF file. 
General Procedures. All the reagents were obtained from commercial sources and used as received unless noted otherwise. Acetonitrile and diethyl ether were obtained from a solvent dispenser (PureSolV 400). The synthesis of the compound was carried out using standard Schlenk-line techniques under a nitrogen atomsphere. ${ }^{1} \mathrm{H}$ NMR and ${ }^{19} \mathrm{~F}$ NMR spectra were recorded on a Bruker 500 DPX spectrometer at room temperature. Mass spectra were recorded on a Finnigan Aqua mass spectrometer with electrospray ionization (ESI). IR spectra were acquired on a PerkinElmer UATR spectrum equiped with a single reflection diamond (scan range $400 \mathrm{~cm}^{-1}$ to $4000 \mathrm{~cm}^{-1}$, resolution 4 $\mathrm{cm}^{-1}$ ). UV-Vis spectra were collected using a transmission dip probe with the path length of $0.31 \mathrm{~cm}$ on an Avantes Avaspec-2048 spectrometer with Avalight-DH-S-BAL light source. Elemental analyses were performed by the Microanalytical Laboratory Kolbe in Germany. The magnetic measurements were carried out on a sample of $6.50 \mathrm{mg}$ powder of the compound $\left[\mathrm{Fe}^{\mathrm{II}}{ }_{4}\left(\mathrm{~L}^{1} \mathrm{SSL}^{1}\right)_{2} \mathrm{~F}_{6}(\mathrm{MeCN})_{2}\right]\left(\mathrm{BF}_{4}\right)_{2}$. The sample was mounted on a plastic straw before introduction in a MPMS-XL Quantum Design SQUID magnetometer. The magnetization measurements were performed in a field of $0.5 \mathrm{~T}$ at temperatures from 300 to $2 \mathrm{~K}$. Corrections for the diamagnetism of the sample were calculated using Pascal's constants.[19]

Acknowledgment: F. Jiang gratefully acknowledges the Chinese Scholarship Council (CSC) for a personal grant (No.201406890012). We thank Mr. Jos van Brussel and Mr. Anne Geert Volbeda for the ESI-MS analysis. Mr. Fons Lefeber is thanked for assistance with NMR spectroscopy. Dr. Aymen Ben Hamida is acknowledged for SQUID measurement. Dr. Sylvestre Bonnet, Mr. Erik van Geest, and Ms. Nicole Smits are thanked for helpful discussions.

Supporting Information Available: Electronic supplementary information (ESI) available: The crystallographic and refinement data of the compound $\left[\mathrm{Fe}^{\mathrm{II}}{ }_{4}\left(\mathrm{~L}^{1} \mathrm{SSL}^{1}\right)_{2} \mathrm{~F}_{6}(\mathrm{MeCN})_{2}\right]\left(\mathrm{BF}_{4}\right)_{2}(\mathrm{CCDC}$ 1820684). UV-Vis and ESI-MS spectra of the compound $\left[\mathrm{Fe}^{\mathrm{II}}{ }_{4}\left(\mathrm{~L}^{1} \mathrm{SSL}^{1}\right)_{2} \mathrm{~F}_{6}(\mathrm{MeCN})_{2}\right]\left(\mathrm{BF}_{4}\right)_{2}$. Supplementary data associated with this article can be found online at XXXX.

\section{References:}

[1] B.L. Pagenkopf, E.M. Carreira, Chem. Eur. J., 5 (1999) 3437-3442.

[2] K.S. Pedersen, M.A. Sørensen, J. Bendix, Coord. Chem. Rev., 299 (2015) 1-21.

[3] T. Birk, ChemistryOpen, 2 (2013) 13-16.

[4] S.C. Lee, R. Holm, Inorg. Chem., 32 (1993) 4745-4753.

[5] E.C. Ording-Wenker, M.A. Siegler, E. Bouwman, Inorg. Chim. Acta, 428 (2015) 193-202.

[6] J. Ackermann, F. Meyer, H. Pritzkow, Inorg. Chim. Acta, 357 (2004) 3703-3711.

[7] J. Manzur, A. Vega, A.M. García, C. Acuña, M. Sieger, B. Sarkar, M. Niemeyer, F. Lissner, T. Schleid, W. Kaim, Eur. J. Inorg. Chem., 2007 (2007) 5500-5510.

[8] D.L. Reger, A.E. Pascui, M.D. Smith, J. Jezierska, A. Ozarowski, Inorg. Chem., 51 (2012) 1182011836 . 
[9] D.L. Reger, R.P. Watson, J.R. Gardinier, M.D. Smith, P.J. Pellechia, Inorg. Chem., 45 (2006) 10088-10097.

[10] E. Tomat, L. Cuesta, V.M. Lynch, J.L. Sessler, Inorg. Chem., 46 (2007) 6224-6226.

[11] M. Taki, S. Teramae, S. Nagatomo, Y. Tachi, T. Kitagawa, S. Itoh, S. Fukuzumi, J. Am. Chem. Soc., 124 (2002) 6367-6377.

[12] E.C. Ording-Wenker, M.A. Siegler, M. Lutz, E. Bouwman, Dalton Trans., 44 (2015) 1219612209.

[13] J. Oliver, D. Mullica, B. Hutchinson, W. Milligan, Inorg. Chem., 19 (1980) 165-169.

[14] L.R. Widger, Y. Jiang, M.A. Siegler, D. Kumar, R. Latifi, S.P. de Visser, G.N. Jameson, D.P. Goldberg, Inorg. Chem., 52 (2013) 10467-10480.

[15] T. Kiczenski, J.F. Stebbins, Fluorine sites in calcium and barium oxyfluorides: F-19 NMR on crystalline model compounds and glasses, J. Non-Cryst. Solids, 306 (2002) 160-168.

[16] A. Zheng, S.-B. Liu, F. Deng, J. Phys.Chem. C, 113 (2009) 15018-15023.

[17] S. Bonnet, M.A. Siegler, J.S. Costa, G. Molnár, A. Bousseksou, A.L. Spek, P. Gamez, J. Reedijk, Chem. Commun., (2008) 5619-5621.

[18] M. Guichelaar, J. Van Hest, J. Reedijk, Inorg. Nucl. Chem. Lett., 10 (1974) 999-1004.

[19] G.A. Bain, J.F. Berry, J. Chem. Educ., 85 (2008) 532. 